\title{
Measuring Technical Efficiency in A Sample Public Universities in Ethiopia: A Data Envelopment Analysis
}

\author{
Obsa Teferi \\ Department of Accounting and Finance, Hawassa University, Ethiopia
}

\begin{abstract}
This paper uses data envelopment analysis to examine the technical efficiency (TE) of 20 departments in the period 2014/2015-2015/2016. To shed light on the causes of variations in efficiency, TE is decomposed into pure technical efficiency and scale efficiency. The input variable is total number of staff (academic and nonacademic), whereas the output variable is total number of students (under graduate and post graduate). The study adopts nonparametric Data Envelopment Analysis (DEA) input-orientation (i.e. both CCR \& BCC models) to measure the relative technical efficiency of departments and Malmquist productivity index (MPI) output-orientation to measure the productivity gains of departments over time. Under CCR model a 5 percent of the sample department was relatively efficient where as a 95 percent were inefficient. In addition, in 2014/15, the number of technical efficient departments was four (4), about 20 percent of the sample when VRS TE is assumed and one (1), about 5 percent when CRS TE is assumed. The Malmquist index measures are also decomposed into two components: technical efficiency change and technological change. Technical efficiency change is further decomposed into pure technical efficiency change and scale efficiency change. On average the sample departments found with increased technical efficiency score. All departments had shown deterioration of technology in the study period

Keywords Data Envelopment Analysis, Malmquist Productivity Index, Technical Efficiency, Public Universities DOI: $10.7176 / \mathrm{JEP} / 11-28-03$

Publication date:October $31^{\text {st }} 2020$

\section{Introduction}

In Ethiopia the number of students, enrolling in higher educational institution is highly increasing from year to year. Since 2000, Ethiopiaee shigher education sector has grown from two public universities to 33 today. From 2010, the number of students in each public university has doubled. It is estimated that Ethiopia se $^{\text {gross enrolment }}$ ratio (GER) has increased by 800 percent between 2000 and 2013. Ethiopia aims to be a middle-income country by 2025 and has the Sub- Saharan African average GER (6 percent in 2008) as its target (Rayner and Ashcrof, 2013).

The reality on ground regarding public universities in Ethiopia is expansion via scattering colleges, institutions and campus. However, there is a shortage of suitably experienced and qualified staff in Ethiopia to meet current demand for education and research by expansion. As the sector expands, there will be a higher need commensurate resources or the additional workload, which will negatively affect the quality of the university. Primarily paying significant attention on expansion without testing efficiency would result in the short term less quality and finally would suffer from various problems (Wondwosen Tamrat, 2011).Many studies have done on technical efficiency of public universities for example, Elsewhere Hashimoto and Cohn (1997) have investigated Japanese universities and McMillian and Debasish (1997) have investigated Canadian universities.

There is a dearth of empirical analysis of the Australian universities. The main focus has been on estimating cost functions: Lloyd (1994), Lloyd et al. (1993), Selby-Smith (1975) and Throsby (1986) or output of specific departments Fox and Milbourne (1999) and Towe and Wright (1995). Coelli (1996a) and Madden, Savage and Kemp (1997) used DEA to measure efficiency. Madden et al. (1997) investigated the efficiency of economics departments for the years 1987 and 1991. Empirical analysis of the performance of universities typically takes the form of estimating cost functions with the focus on economies of size and scope, or on analysis of efficiency using Data Envelopment Analysis (DEA) or frontier functions. Most of this work has focused on the UK or the US. Key studies include those by Cohn, Rhine and Santos (1989), De Groot, McMahon and Volkwein (1991), Dunbar and Lewis (1995), King(1997) and Nelson and Hevert (1992).

The study on technical efficiency of higher educational institution seem important in the fact that higher education need to be efficient to meet the current demand for education and conduct research that can in part reduce the community problems. Being an efficient implies able to accomplish objectives by producing more output from the existing input without quality reduction. This very curtain area needs to get solid attention of policy makers, higher officials and managing body of higher universities. Therefore, this study may provide hint on efficiency of a sample universities using data envelopment analysis.
\end{abstract}

\subsection{General Objective}

The main objective of the study is to investigate the relative technical efficiency of a sample Universities in Ethiopia using data envelopment analysis (DEA). 


\subsection{Specific Objectives}

- To measure the technical efficiency scores of sample departments.

- To determine the source of the technical inefficiency in sample departments

- To identify the required improvement needed by the inefficient departments to become efficient.

\section{Related Literature Review}

\subsection{The Concept of Efficiency}

In economics, the term economic efficiency refers to the use of resources so as to maximize the production of goods and service. In absolute terms, the situation can be called economically efficient if: (1) No one can be made better off without making someone else worse off, (2) No additional output can be obtained without increasing the amount of inputs, and (3) Production proceeds at the lowest possible per-unit cost (Sullivan and Sheffrin, 2007). 2.1.1. Categorization of Efficiency

Efficiency can be categorized into technical, allocative or into the combination of the two (i.e. total economic efficiency) based on scope of efficiency targeted (see Farrell, 1957; Bhat et al, 2001)

Technical Efficiency means producing maximum output with given inputs; or equivalently, using minimum inputs to produce a given output (Farrell, 1957).

Allocative efficiency deals with the minimizing of cost of production with proper combination of inputs for a given level of outputs and a set of input prices, assuming that the entity examined is working with the full technical efficiency.

Total Economic Efficiency represents a combination of technical and allocative efficiency (Coelli, 1996). An entity will only be economically efficient (cost efficient) if it is both technically and allocative efficient. That means, cost (total economic) efficiency is the product of the technical and allocative efficiency scores (Bhat et al., 2001).

\subsection{Non-parametric Approach}

Non-parametric approach is based on the concept of efficiency similar to one in the parametric approach but differs from it since this approach does not require any pre-specified function. It takes the data of the actual operations of the firms under study and frontier is formed as the piecewise linear combination of the "most efficient observations." Thus, efficiency so determined is relative to the "observed best", rather than an absolute value (Gupta et al 2003 \& Chansern, 2008).

\subsection{Data Envelopment Analysis (DEA)}

DEA is an analytical technique that can be used to assist in identifying best practice performance in the use of resources amongst a group of like organizations. Such identification can highlight where the greatest gains can be made from improvements in efficiency and help institutions to achieve their full potential. Measurement tools like DEA are useful in situations where government bodies operate in markets, which are distorted by regulated prices, subsidies and a lack of contestability. In these cases the usual market indicators of performance, like profitability and rates of return, cannot be used to gauge an institution "s economic performance accurately. Despite this, governments and the general public are still concerned that these institutions operate in an efficient manner. In these situations DEA provides a comparative monitoring that identifies variations and hence provides encouragement and direction for performance improvement.

Technical efficiency means that an institution cannot produce more output from its existing inputs. In the case of universities, this means that the technically efficient university is not able to deliver more teaching plus research output (without reducing quality) given its existing labor, capital and other inputs. Technical efficiency is a valid performance measure, as the provision of education and research by universities at a given level of quality, within resource constraints is a major objective of universities. Some authors argue that, next to the delivery of quality education, technical efficiency is probably the only valid measure of performance of tertiary institutions (see Pestieau \& Tulkens, 1993).

\subsection{Advantage and Limitation of DEA}

The efficiency of a machine can be analyzed by contrasting its actual output to its engineering specifications. However, when we consider service organizations, we generally do not know what the optimum efficiency is and therefore we cannot determine whether a service unit is absolutely efficient. DEA enables us to compare several service units with each other and determine their relative efficiency. The main strength of DEA is its objectivity, i.e. DEA provides efficiency ratings based on numerical data, and not by using subjective opinions of people. DEA is certainly a very valuable evaluation tool that makes the maximum possible objective use of the available data. DEA produces a single score for each unit, which makes the comparison easy. Unlike ratios, it can accommodate multiple inputs and multiple outputs. These inputs and outputs can be in different units of measurement. 
In contrast to regression methods, DEA focuses on individual observations and optimizes the performance measure of each DMU. A prior knowledge of weights or prices for inputs and outputs is not required in DEA; however, managerial judgment can be accommodated when desired.

Another DEA advantage that attracts analysts and management is its ability to identify the potential improvement for each inefficient DMU. For units enveloped by the frontier, the inefficient units, DEA compares the unit with a convex combination of DMUs located on. The frontier enables the analyst to indicate the sources and the level of inefficiency for each of its inputs and outputs (Charnes et al., 1978).

The same features that make DEA a powerful tool can also create problems. The following limitations must be considered when choosing whether or not to use DEA (Bhat2001).

a. Since DEA is an extreme point technique, noise (even symmetrical noise with zero mean) such as measurement error can cause significant problems.

b. DEA is good at estimating "relative" efficiency of a DMU but it converges very slowly to "absolute" efficiency. In other words, it can tell you how well you are doing compared to your peers but not compared to a "theoretical maximum."

As efficiency scores in DEA are obtained after running a number of Linear Programming problems, it is not easy to explain intuitively the process of DEA for the case of more than two inputs and outputs to a nontechnical audience. This cannot be a problem in current technology when different software can be easily applied to get efficiency score

\subsection{Empirical Literature}

Several studies have been carried out on measuring the university efficiency using the frontier analysis methods. This section critically reviews some of the studies which measures efficiency of universities in various countries

Research done on universities in the UK include those by Athanassopoulos and Shale (1997), Glass, McKillop and Hyndman (1995a, 1995b), Johnes (1993) and Johnes and Johnes (1995).

Elsewhere Hashimoto and Cohn (1997) have investigated Japanese universities and McMillian and Debasish (1997) have investigated Canadian universities. There is a dearth of empirical analysis of the Australian universities. The main focus has been on estimating cost functions; see Lloyd (1994), Lloyd, Morgan and Williams (1993), Selby-Smith (1975) and Throsby (1986) or output of specific departments Fox and Milbourne (1999) and Towe and Wright (1995). Coelli (1996a) and Madden, Savage and Kemp (1997) used DEA to measure efficiency. Madden et al. (1997) investigated the efficiency of economics departments for the years 1987 and 1991. However, they analyzed only 24 of the 36 government universities, and the measurement of efficiency was restricted to only one department. Coelli (1996a) used 1994 data to explore the efficiency of universities overall, as well as separately for administration and for academic activities, but considered only a limited number of output measures

Barrow's (1991) study of schools in England tested various forms of the cost frontier and found the level of efficiency to be sensitive to the method of estimation. In their study of technical inefficiency in elementary schools in New York, Wyckoff and Lavinge (1991) estimate the production function directly and find that the index of technical inefficiency depends on the definition of educational output. For example, if output is measured by the level of cognitive skill of students rather than their college entrance test scores (i.e., the ACT, SAT, or any other type of composite test score consisting of reading, writing, and mathematics skills), the index of technical inefficiency based on each output measure will be different. Grosskopf et al. (1991) used a stochastic frontier and distance function to measure technical and allocative efficiency in Texas school districts and concluded that they were technically efficient

\section{Materials and Methods}

\subsection{Description of the Study Area}

Government universities have been increasing in number and size to satisfy demand for educated persons in the country. Currently there are 33 public universities with 11 opening soon. The universities have a large number of undergraduate and postgraduate programs under multi disciplines. Besides teaching and learning activity all universities in part, take solving communities problems in conducting research, projects, providing training and other social services. Nevertheless, the important issue that should not be over looked is the efficiency of universities. A university may be technically efficient but it may still be producing too little or too much output. In other words, larger universities may be still inefficient in education delivery service. More universities are multi- campus universities and receive significant funds from federal government for teaching -learning and research activities.

The study focused on two government universities: Hawassa University and Dilla University Hawassa University has more than forty departments under five campuses. It is one of the biggest universities in Ethiopia. Dilla University has the sample colleges and departments for the current study. Therefore, the researcher assumed the ages of sample colleges and departments of the universities. 


\subsection{Sample and Sampling technique}

An extensive study can be done in the future incorporating all universities. Nevertheless, the current study purposely focused on two universities assuming that they have close ages, number of disciplines and number of students in the sample departments. The researcher also assumes that if one university is considered for the study, reliable results may not be observed. The reasons would be (1) Departments are followed under a common academic system or one academic unit say Vice president for Academic affairs. They are under common management philosophy and control. Academic issues and cases are processed and handled in the same fashion among departments (2) the departments are adhere to one academic calendar (3) A working Environment is the same (4) departments under one university share many academic issues together which reduce differences among them. These things added together may bias the study therefore, it is better to take two or more universities to control for the bias. The study sample three colleges of the universities: College of business and economics, College of Social science, college of competition science, college agriculture and institute of technology. Twenty departments were taken i.e., eight departments from Dilla university and 12 departments from Hawassa University.

\subsection{Method of Data Analysis}

The current study utilized the DEA based on the input orientated analysis, in order to identify sources of inefficiency at the input level, which is under direct control of college management. Alssaleh, (2012) stated that in firms where the focus is on technical efficiency, input-orientated could be an appropriate choice. To measure the sample departments' technical efficiency, both the Charnes-Cooper-Rhodes (CCR) and Banker-CharnesCooper (BCC) models are used. In CCR model, I estimate overall technical efficiency of departments. However, scale efficiency is determined from the ratio of overall and pure technical efficiencies. The study used the DEAP version 2.1 software tool to measure the technical efficiency

\subsection{Data Envelopment Analysis Model}

Data envelopment analysis has been frequently used to measure the relative efficiency of universities. Measuring college efficiency requires selection of appropriate input and output variables. Universities are multi-output organizations producing research, teaching and community services. Measures of teaching output include the number of equivalent full-time students (the number of post-graduate and under-graduate degrees). Initially the study plans to use two input measures namely, the total number of academic staff (full-time equivalent) and the number of non-academic staff (fulltime equivalent), expenditure on all other inputs other than labor inputs include expenditure on energy, non-salary academic and administration services, buildings and grounds, libraries and student services. However, expenditure incurred particular at department/school level is not identified because most of the sample departments do not know their budget as they are not considered as a cost center. Thus I have not got data on the variable.

\subsection{Model Specification}

The study applied CCR and BCC models to estimate the relative efficiency and Malmquist productivity index in order to measure total factor productivity change.

$$
\text { Efficiency }=\frac{\text { weighted sum of outputs }}{\text { Weightedsum of inputs }}
$$

\subsection{CCR \& BCC Efficiency Models}

In order to estimate efficiency scores and identify sources of inefficiency, the study will apply input-oriented DEA. First the researcher employs the CCR model which assumes CRS according to the following equation (Charnes et al., 1978):

$$
\left.\min \theta-\varepsilon \mid \sum_{i=1}^{m} \mathrm{Si}^{-}-\sum_{r=1}^{s} \mathrm{Sr}^{+}\right\rfloor
$$

Subject to:

$$
\begin{gathered}
\sum_{j=1}^{n} \mu \mathrm{j} x i+\mathrm{Si}^{-}=\theta k x i k \quad i=1, \ldots, m \\
\sum_{j=1}^{n} \mu j y r j-\mathrm{Sr}^{+}=y r k \quad r=1, \ldots, \mathrm{s}
\end{gathered}
$$

The scalar variable ${ }^{\theta}$ is the proportional reduction which should be applied to all inputs of DMU, in order to

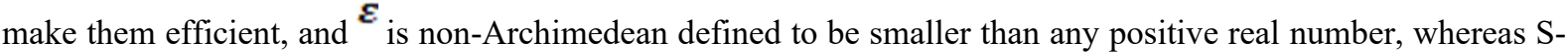
and $\mathrm{S}+$ are " Slack variables" and a standard Linear

Programming terminology for additional variables added to the model in order to convert inequality constraints to equality constraints. This terminology in DEA is also used when additional improvement is possible 
in specific inputs or outputs.

Coelli (1996) stated that the use of the CRS specification when some of the DMUs are not running at optimal scale will result in measures of technical efficiency which are mixed up with scale efficiency. To overcome this problem, Banker et al (1984) suggested their model known as the BCC model. It improved the CCR model by introducing a variable that represents the returns to scale. The BCC model allows a calculation of technical efficiency that is free from the scale efficiency effects. In the BCC model, the formulation is written as below (Banker et al. 1984);

$$
\left.\min \theta-\varepsilon \mid \sum_{i=1}^{m} \mathrm{Si}^{-}+\sum_{r=1}^{s} \mathrm{Sr}^{+}\right\rfloor
$$

Subject to:

$$
\begin{gathered}
\sum_{j=1}^{n} \mu j x i+S i^{-}=\theta k x i k \quad i=1, \ldots, m \\
\sum_{j=1}^{n} \mu j y r j-\mathrm{Sr}^{+}=y r k r=1, \ldots, \mathrm{s} \\
\sum_{j=1}^{n} \mu j=1, j=1, \ldots n \\
\mu j, \mathrm{~S}^{+}, \mathrm{S}^{-} \geq 0 j=1, \ldots n
\end{gathered}
$$

A DMU is BCC-efficient if and only if $\theta^{*}=1$ and all slacks are zero. The envelopment surface in BCC mode1 is variable returns to scale and this is the result of the presence of the convexity constraint $\left(\sum_{j=1}^{n} \mu j=1\right)$.

\section{Results and Discussion}

This section presents the detail discussion and analysis of the findings of the study. In put (number of staff) and output (number of students) components of twenty departments over 2014/2015 and 2015/2016 are used for the measure of relative technical efficiency (TE), pure technical efficiency (PTE) and scale efficiency (SE). The same data were used to compute the total factor productivity (TFP) change during the study period.

\subsection{Descriptive Statistics}

Table 1 presents descriptive statistics of input variable and out variable. The mean value of output variable (number of student) during the observation period was 454 , while the minimum and maximum number were 56 and 1,188 respectively. It indicates a huge variation among the sample departments. Some departments were relatively large in size whiles some departments were small

Table 1. Descriptive Statistics

$\begin{array}{lllll}\text { Variable } & \text { Obs. } & \text { Mean } & \text { Min } & \text { Max } \\ \text { Number of student } & 40 & 454 & 56 & 1188 \\ \text { Number of staff } & 40 & 27 & 3 & 67\end{array}$

The sample departments in average had 27 numbers of staff with minimum 3 and maximum 67 staffs during the observations under study. This is also another indication for the existence of great variation among departments. Basically most departments are market and policy driven. For example a 70/30 model favors increasing an intake capacity of natural science stream by limiting social science. In the social science category, collage of business and economics takes higher portion because of high demand in market.

\subsection{Results of Data Envelopment Analysis (DEA) Models}

This section discusses results obtained from DEA models: CCR model with the assumption of constant return to scale (CRS) and BCC model under the assumption of variable return to scale (VRS). Sarkis (2000) argued that the use of the CCR and BCC models together help to determine the overall technical and scale efficiencies of departments and whether the data exhibits varying returns to scale. The study employed input oriented approach assuming that minimizing usage of input keeping output constant is more sound able than increasing output without reducing input usage. Because it can be assumed that Universities could potentially impact its input than output. Alssaleh, (2012) stated that in firms where the focus is on technical efficiency, input-orientated could be an appropriate choice.

The productivity growth of the sampled departments over the observation period (2014/15 - 2015/2016) is also measured under Malmquist Productivity Index (MPI). The technical efficiency obtained from a CRS decomposed into two components: Pure technical inefficiency and Scale inefficiency. Technical efficiency (TE) is calculated by a CCR model, whereas a BCC model calculates pure technical efficiency (PTE). If there is 
difference between the two efficiency scores, there is scale inefficiency which is computed from the ratio of technical efficiency to pure technical efficiency (TE/PTE).

This study measured a relative efficiency by comparing the best practice department in the sample. The source of inefficiency can be computed by comparing the relative sizes of various efficiency measures. If pure technical efficiency is greater than scale efficiency, then inefficiency is caused by scale inefficiency

\subsection{CCR Models Results}

The CCR model measures the overall or technical efficiency under the assumption of constant return to scale. Constant return to scale assumes that a change in an input changes an output proportionately. Table 2 presents the overall efficiency of the sampled departments

Table 2. Technical Efficiency of Departments Using CCR model/ CRS Assumption

\begin{tabular}{|c|c|c|}
\hline \multicolumn{3}{|c|}{ Technical Efficiency (TE) } \\
\hline School/Department & $2014 / 2015$ & $2015 / 2016$ \\
\hline 1 & 0.319 & 0.319 \\
\hline 2 & 0.413 & 0.518 \\
\hline 3 & 0.468 & 1.000 \\
\hline 4 & 0.179 & 0.154 \\
\hline 5 & 0.667 & 0.694 \\
\hline 6 & 0.284 & 0.424 \\
\hline 7 & 0.256 & 0.295 \\
\hline 8 & 0.476 & 0.408 \\
\hline 9 & 0.780 & 0.756 \\
\hline 10 & 0.775 & 0.920 \\
\hline 11 & 0.462 & 0.533 \\
\hline 12 & 0.536 & 0.529 \\
\hline 13 & 0.413 & 0.355 \\
\hline 14 & 0.431 & 0.432 \\
\hline 15 & 0.346 & 0.368 \\
\hline 16 & 0.547 & 0.510 \\
\hline 17 & 0.418 & 0.503 \\
\hline 18 & 0.132 & 0.297 \\
\hline 19 & 1.000 & 0.450 \\
\hline 20 & 0.490 & 0.482 \\
\hline Mean & 0.470 & 0.497 \\
\hline
\end{tabular}

As can be observed in Table 2, in 2014/2015 a 5 percent of the sample department was relatively efficient where as a 95 percent were inefficient. The efficient department has been efficiently utilized its input. It indicates the department success in allocating and converting its input to output. On average the sample department relative technical efficiency score was 0.470 suggesting that about 53 percent of their input were poorly utilized or excess input used in the year. The departments would have decreased usage of their inputs by 53 percent to be efficient. About 37 percent of the inefficient departments had efficiency score more than the mean 0.470 . In 2015/2016 only one department relatively efficient while the remaining 19 departments were inefficient. However, the average technical efficiency rose to 0.497 in $2015 / 2016$. Out of the inefficient department, 8 departments had efficiency score more than the mean. Overall results show that the sample departments had not properly utilized their resources during the period under the study.

\subsection{BCC Model Results}

The BCC model evaluates whether increasing, decreasing or constant returns to scale would be taken to improve the efficiency value found. Constant returns to scale (CRS) arise when a percentage increase in inputs produces the same percentage increase in outputs. However, variable returns to scale (VRS) occurs when a proportionate increase in inputs produces a smaller (larger) proportionate increase in outputs. This assumption of BCC model decomposed into: decreasing return to scale and increasing return to scale. In a decrease return to scale an increase in input produces a smaller increase in output. An increase return to scale arises when an increase in inputs yield a larger increase in output.

The CRS technical efficiency is divided into pure technical efficiency and scale efficiency in BCC model. Pure technical efficiency measures the extent to which a department can decrease its inputs (in fixed proportion) while still remaining within the VRS frontier. Thus technical efficiency measures the department's overall success at utilizing its inputs. Scale efficiency measures the extent to which a firm can reduce inputs by moving to a part of the frontier with more beneficial returns to scale characteristics. 
The decomposition is needed to identify the sources of inefficiency by comparing pure technical efficiency and scale efficiency. When pure technical efficiency is higher than that of scale efficiency, the source of inefficiency is due to scale inefficiency (inappropriate selection of scale size). In other words, if there is a difference between the technical efficiency score (CRS technical efficiency and VRS pure technical efficiency), then this demonstrates scale inefficiency. Conversely, if scale efficiency is higher than pure technical efficiency, then the source of inefficiency is due to poor utilization of inputs, i.e., pure technical inefficiency

Table 3 reports results obtained from BCC model variable return to scale (VRS). The results entail CRS technical efficiency, VRS technical efficiency and scale efficiency. In 2014/15, the number of technical efficient departments was four (4), about 20 percent of the sample when VRS TE is assumed and one (1), about 5 percent when CRS TE is assumed. Among the four technician efficient departments, only one department is scale efficient suggesting that appropriate selection of inputs and operating on most productive scale size. Whilst three departments are scale inefficient. This reflects that these departments used inappropriate selection of resource scale size (too large or too small)

Table 3. Technical Efficiency (CRSTE), Pure Technical Efficiency (VRS TE) and Scale Efficiency(SE)

\begin{tabular}{|c|c|c|c|c|c|}
\hline Year & School/Department & CRSTE & VRSTE & SCALE & TYPE \\
\hline \multirow{21}{*}{$\begin{array}{c}2014 / 2015 \\
2007 \text { E.C }\end{array}$} & 1 & 0.319 & 0.378 & 0.844 & Increasing \\
\hline & 2 & 0.413 & 0.471 & 0.875 & increasing \\
\hline & 3 & 0.468 & 1.000 & 0.468 & Increasing \\
\hline & 4 & 0.179 & 0.209 & 0.857 & increasing \\
\hline & 5 & 0.667 & 0.825 & 0.808 & Decreasing \\
\hline & 6 & 0.284 & 0.305 & 0.931 & decreasing \\
\hline & 7 & 0.256 & 0.328 & 0.779 & increasing \\
\hline & 8. & 0.476 & 0.493 & 0.967 & Decreasing \\
\hline & 9 & 0.780 & 0.952 & 0.819 & Decreasing \\
\hline & 10 & 0.775 & 1.000 & 0.775 & Decreasing \\
\hline & 11 & 0.462 & 0.574 & 0.806 & Decreasing \\
\hline & 12 & 0.536 & 0.675 & 0.794 & Decreasing \\
\hline & 13 & 0.413 & 0.494 & 0.836 & Decreasing \\
\hline & 14 & 0.431 & 0.523 & 0.824 & Decreasing \\
\hline & 15 & 0.346 & 0.368 & 0.941 & Decreasing \\
\hline & 16 & 0.547 & 0.632 & 0.866 & Decreasing \\
\hline & 17 & 0.418 & 0.420 & 0.995 & Increasing \\
\hline & 18 & 0.132 & 0.143 & 0.924 & Increasing \\
\hline & 19. & 1.000 & 1.000 & 1.000 & - \\
\hline & 20 & 0.490 & 1.000 & 0.490 & Decreasing \\
\hline & Mean & 0.470 & 0.589 & 0.830 & \\
\hline \multirow{21}{*}{$2015 / 2016$} & 1 & 0.319 & 0.320 & 0.998 & Decreasing \\
\hline & 2. & 0.518 & 0.534 & 0.971 & Decreasing \\
\hline & 3. & 1.000 & 1.000 & 1.000 & - \\
\hline & 4 & 0.154 & 0.155 & 0.992 & Decreasing \\
\hline & 5 & 0.694 & 0.753 & 0.922 & Decreasing \\
\hline & 6 & 0.424 & 0.456 & 0.930 & Decreasing \\
\hline & 7 & 0.295 & 0.333 & 0.886 & Increasing \\
\hline & 8 & 0.408 & 0.423 & 0.965 & Decreasing \\
\hline & 9 & 0.756 & 0.818 & 0.924 & Decreasing \\
\hline & 10. & 0.920 & 1.000 & 0.920 & Decreasing \\
\hline & 11 & 0.533 & 0.575 & 0.927 & Decreasing \\
\hline & 12 & 0.529 & 0.573 & 0.922 & Decreasing \\
\hline & 13 & 0.355 & 0.379 & 0.936 & Decreasing \\
\hline & 14 & 0.432 & 0.464 & 0.929 & Decreasing \\
\hline & 15 & 0.368 & 0.392 & 0.939 & Decreasing \\
\hline & 16 & 0.510 & 0.544 & 0.936 & Decreasing \\
\hline & 17 & 0.503 & 0.532 & 0.945 & Decreasing \\
\hline & 18 & 0.297 & 0.321 & 0.927 & Decreasing \\
\hline & 19 & 0.450 & 0.477 & 0.942 & Decreasing \\
\hline & 20. & 0.482 & 1.000 & 0.482 & Decreasing \\
\hline & Mean & 0.497 & 0.552 & 0.920 & \\
\hline
\end{tabular}


When look at the overall results, nineteen (19) departments had scale inefficiency. The source of technical inefficiency of five arise from scale inefficiency. This indicates the departments operate at an inappropriate scale. The remaining fourteen departments' inefficiency caused by pure technical inefficiency. Eleven (11) departments experienced a decreasing return to scale, i.e., a proportionate increase in inputs produces a lower proportionate increase in outputs. This implies that the departments have supra-optimal scale size (i.e. operate at the rising portion of long-run average cost curve) and thus, downscaling is needed for achieving efficiency frontier. These departments appear to be too large. In contrast, Eight (8) departments experienced an increasing return to scale suggesting that a proportionate increase in inputs yields a larger proportionate in inputs. These departments would improve their efficiency by expanding the scale of operation.

About 15 percent of the sample departments were efficient when VRS TE is assumed in 2015/16. Only one department is found efficient when CRS TE is assumed. The number of relatively technical efficient departments declined in this year. The source of inefficiency is pure technical inefficiency i.e., poor utilization of inputs. It reveals a large amount of inputs were inappropriately consumed during the year. On average the departments would have reduced usage of their inputs by 44.8 percent to be efficient. All inefficient departments experienced a decreasing return to scale (too large).

\subsection{Malmquist Index Summary Of Results}

Malmquist evaluates total productivity change over time. Productivity change decomposed into two components. Technical change which reflect to the improvement and deterioration in the performance of best practice. The other is technical efficiency and it reflects the convergence toward or the divergence from best practice on the part of the remaining firms (Mansor \& Radam, 2000). The value of the decomposition is that it provides information on the source of overall productivity change in the firms.

The Malmquist index can be decomposed to capture the two components, technological change and technical efficiency change. Technical efficiency can be further decomposed into a pure technical efficiency and a scale efficiency change components. The change in technical efficiency is described as the efficiency in reaching to the production limit and technological change described as the curve shift in productivity limit. If the value of Malmquist index or any of its components is less than 1, that denotes regress or deterioration in performance, whereas values greater than one denote improvements in the relevant performance (Fare et al., 1994).

Table 4 presents the Malmquist index summary of departments' means. With regards to technical efficiency change over the period 2014/15 and 2015/2016. About elven departments observed with an increase in annual average efficiency. Whiles five departments experienced a decline annual average technical efficiency. The technical efficiency of four departments remained constant. On average the sample departments found with increased technical efficiency score. In addition, all departments had shown deterioration of technology in the study period. On average the deterioration amount was about 7.7 percent suggesting that a decrease in total productivity growth by 0.3 percent.

As can be seen in Table 4 eight departments showed an increase in total productivity growth while twelve departments are seen with declined productivity growth. The mean of scale efficiency suggests an improvement of efficiency among departments. Nevertheless, the pure technical efficiency declined and the source of inefficiency is relative technical inefficiency.

Table 4. Malmquist Index Summary of Firm means

\begin{tabular}{|c|c|c|c|c|c|c|}
\hline No & School/Department & Effch & Techch & Pech & Sech & Tfpch \\
\hline 1 & 1. & 1.000 & 0.923 & 0.846 & 1.182 & 0.923 \\
\hline & 2 & 1.256 & 0.923 & 1.132 & 1.109 & 1.159 \\
\hline & 3 & 2.137 & 0.923 & 1.000 & 2.137 & 1.971 \\
\hline & 4 & 0.858 & 0.923 & 0.742 & 1.158 & 0.792 \\
\hline & 5 & 1.042 & 0.923 & 0.913 & 1.141 & 0.961 \\
\hline & 6 & 1.494 & 0.923 & 1.496 & 0.999 & 1.378 \\
\hline & 7 & 1.155 & 0.923 & 1.016 & 1.136 & 1.065 \\
\hline & 8 & 0.856 & 0.923 & 0.858 & 0.997 & 0.789 \\
\hline & 9 & 0.969 & 0.923 & 0.859 & 1.128 & 0.894 \\
\hline & 10 & 1.188 & 0.923 & 1.000 & 1.188 & 1.096 \\
\hline & 11 & 1.152 & 0.923 & 1.002 & 1.150 & 1.063 \\
\hline & 12 & 0.986 & 0.923 & 0.849 & 1.161 & 0.910 \\
\hline & 13 & 0.859 & 0.923 & 0.768 & 1.119 & 0.793 \\
\hline & 14 & 1.002 & 0.923 & 0.888 & 1.128 & 0.924 \\
\hline & 15 & 1.065 & 0.923 & 1.066 & 0.998 & 0.982 \\
\hline & 16 & 0.932 & 0.923 & 0.861 & 1.082 & 0.859 \\
\hline & 17 & 1.203 & 0.923 & 1.266 & 0.950 & 1.110 \\
\hline
\end{tabular}




\begin{tabular}{|c|c|c|c|c|c|c|}
\hline No & School/Department & Effch & Techch & Pech & Sech & Tfpch \\
\hline & 18 & 2.253 & 0.923 & 2.245 & 1.003 & 2.078 \\
\hline & 19 & 0.450 & 0.923 & 0.477 & 0.942 & 0.415 \\
\hline & 20 & 0.983 & 0.923 & 1.000 & 0.983 & 0.907 \\
\hline & Mean & 1.081 & 0.923 & 0.968 & 1.116 & 0.997 \\
\hline
\end{tabular}

[Note that all Malmquist index averages are geometric means]

Notes: - Effch - technical efficiency change

Techch - technological change

Pech - pure technical efficiency change

Sech - scale efficiency change

Tfpch - total factor productivity change

\section{Conclusions and Direction for Further Study}

\subsection{Conclusions}

This paper uses data envelopment analysis to examine the technical efficiency (TE) of 20 departments in the period 2014/15-2015/2016. The average relative technical efficiency score was less than 0.5 in the observation periods suggesting that the sample departments poorly utilized inputs under both CRS and VRS model. The Malmquist approach notes that all departments had experienced deterioration of technology.

Relying on the results found I argue that with the aim of making universities more responsive to students' demand for higher education, and to encourage them to exploit any spare capacity, an increasing proportion of public funds would henceforth be provided in the form of fee income rather than as block grants. The government should also advise higher education to provide wider access to its services, and be more responsive to the needs of industry and commerce, less dependent on public funding and more cost-conscious in managing its resources

\subsection{Direction for Future Studies}

The focused on two universities only that would not be sufficient to generalize the findings so that it can be replied involving more universities. The study employed a single input and out variable (teaching input and output variable). Further study can be done assuming multiple variables for example, research activity (output), and expenditure other than labor (input).

\section{REFERENCESS}

[1] Teshome Yizengaw, (2007) Undergraduate and Graduate degree programs mix and student placement in the expanding higher education system in Ethiopia, policy white paper prepared by Ministry of Education and Ministry of Capacity Building, Addis Ababa, Ethiopia.

[2] Wondwosen Tamrat (2011) Evaluating the Evaluator: HERQA in the Eyes of PHEIs in Ethiopia,

[3] Paper presented at the Conference „The Influence Of HERQA On The Quality And Relevance

[4] Of Ethiopia ${ }^{a c}$ s Higher Education System: Reflections On The Evidence ${ }^{e c}$. Addis Ababa 3rd and 4th May, 2011

[5] Aubyn, M., Pina, A., Garcia,F. \& Pais, J. (2008). Study on the efficiency and effectiveness of public spending on tertiary education Third report (second draft) Economic Papers

[6] Banker, R.D., Charnes, A., and Cooper, W.W.(1984). Some models for estimating technical and scale inefficiencies in DEA. Management Science, Vol.30, No.9, 1078-1092.

[7] Bhat, R., Bhushan, B. and Reuben, E. (2001). An empirical analysis of district hospitals and grant-inaid hospitals in Gujarat state of India, Indian Institute of Management.

[8] Bowlin, William F., Charnes, A., and Cooper, W. W. (2002). Efficiency and effectiveness in DEA: An illustrative application to base maintenance activities in the U.S. air force. Working Papers in cost benefit analysis, Mellon University

[9] Charnes, A., Cooper, W.W., and Rhodes, E. (1978). Measuring the efficiency of decision making units. European Journal of operations research Vol.2, No.6, 429-444.

[10] Coelli, T. (1996). A guide to DEAP Version 2.1, A Data Envelopment Analysis (Computer) Program”, CEPA Working Paper 96/08, University of New England, Australia

[11] Coelli, T., P. Rao and G.E Battese (2002). An Introduction to Efficiency and Productivity Analysis, (London: Kluwer Academic Publishers).

[12] Colwell, R. J. and Davis, E. P. (1992). Output and Productivity in Banking, the Scandinavia journal of economics.

[13] Drake, L. (2001). Efficiency and Productivity change in UK banking. Applied Financial Economics 11, pp 557-571

[14] Sherman HD. measurement of hospital e•ciency using data envelopment analysis. Doctoral dissertation, Harvard University, Dissertation Abstracts International 42(8), 3731A, University Micro®lms No. 8202819, 1981. 